\title{
HIGH VOLTAGE BEAM DISCHARGE IN NITROGEN WITH FAST NEUTRAL ATOM REFLECTION FROM TANTALUM CATHODE
}

\author{
V.S. Boldasov ${ }^{1}$, A.I. Kuzmichev ${ }^{2}$, M.S. Melnichenko ${ }^{3}$, V.M. Shulaev ${ }^{3}$ \\ ${ }^{1}$ Moscow Polytechnic Institute, Moscow, Russia; \\ ${ }^{2}$ Igor Sikorsky Kyiv Polytechnic Institute, Kyiv, Ukraine; \\ ${ }^{3}$ SPE OTTOM, Ltd., Kharkiv, Ukraine \\ E-mail: kuzmichev-kpi@ukr.net; E-mail:ottom@ottom.com.ua
}

The kinetic simulation of high-voltage beam discharge at low pressure of nitrogen is fulfilled. The characteristics of particle flows to the tantalum cathode and back reflection of fast nitrogen atoms are calculated. The reflection coefficient equals tens of percents at voltages up to $100 \mathrm{kV}$. The generation of fast nitrogen atoms may be used for metals and dielectrics nitriding with implantation effect.

PACS: 52.80.Tn, 34.50.Dy

\section{INTRODUCTION}

In electron-ion and plasma engineering and technology, various types of gas discharges are used, a special place among which is occupied by high-voltage lowpressure discharges of the beam type, in which charged particles acquire a large energy comparable to the energy of particles in vacuum accelerators at the same voltages. Such discharges arise and are maintained at $p d$ ( $p$ is the gas pressure, $d$ is the gap between the electrodes) corresponding to the left branch of the Paschen curve [1] and providing the mean free path of charged particles between collisions with gas molecules of the order of $d$. These collisions, although rare, lead to the generation of new particles in the gap (electrons, ions, and fast neutrals after ion recharge). New electrons and ions are accelerated by the electric field, leading to an expansion of the energy spectrum of the particles that bombard the electrodes. Various processes occur on the electrodes caused by high-energy bombardment; of the most important kinetic processes, we note for the cathode - secondary electron emission ( $\gamma$-emission), material sputtering and backscattering (reflection) of fast neutral atomic particles (part of the former bombarding charged and neutral particles), and for the anode - backscattering (reflection) of a part of high-energy electrons [1, 2].

It follows from what has been mentioned that in beam discharges the electrodes are not only collectors of particles, but also diffuse reflectors of high-energy particles. Also, the discharges are generators of fast neutral particles fluxes to the cathode (as neutrals after charge exchange of ions) and to the anode (as reflected atoms of the working gas).

These features of the beam discharges, together with the thermal effect on the electrodes, are of practical interest for nitriding technology using the effects of nitrogen implantation into objects made of both conductive materials and dielectrics. To quantify the effects useful for nitriding, it is advisable to simulate a high-voltage discharge in a nitrogen atmosphere, taking into account the reflection of fast neutral nitrogen atoms from the cathode surface. The given work is devoted to this subject. Tantalum was chosen as a metal reflecting atomic nitrogen, since it is interesting for use in nitriding processes.

\section{PHYSICAL AND KINETIC SIMULATION OF HIGH VOLTAGE LOW PRESSURE DISCHARGE}

\subsection{SIMULATION OF PROCESSES IN GAS GAP}

The used mathematical model is represented by the system (1) of kinetic equations for a planar electrode system and Poisson's equations for an electric field for a direct current power supply mode

$$
\begin{gathered}
v_{x} \frac{\partial f_{e}(x, \vec{v})}{\partial x}-\frac{e}{m} E(x) \frac{\partial f_{e}(x, \vec{v})}{\partial v_{x}}=2 n v \delta\left(v^{2}\right)\left(q_{e}+q_{i}+q_{n}+q_{r}\right), \\
\frac{\partial f_{i}\left(x, v_{x}\right)}{\partial t} v_{x} \frac{\partial f_{i}\left(x, v_{x}\right)}{\partial x}+\frac{e}{M} E(x) \frac{\partial f_{i}\left(x, v_{x}\right)}{\partial v_{x}}=2 n v_{x} \delta\left(v_{x}^{2}\right)\left(q_{e}+q_{i}+q_{n}+q_{r}\right)- \\
\left.-n f_{i}\left(x, v_{x}\right) \sigma_{c e}\left(v_{x}\right) v_{x}+2 n v_{x} \delta\left(v_{x}^{2}\right)\right) f_{i}\left(x, v_{x}^{\prime}\right) \sigma_{c e}\left(v_{x}^{\prime}\right) v_{x}^{\prime} d v_{x}^{\prime}, \\
q_{\alpha}=\int f_{\alpha}\left(x, \vec{v}^{\prime}\right) \sigma_{\alpha}\left(v^{\prime}\right) v^{\prime} d \vec{v}^{\prime}, \alpha=e, r, \\
q_{\beta}=\int f_{\beta}\left(x, v_{x}^{\prime}\right) \sigma_{\beta}\left(v_{x}^{\prime}\right) v_{x}^{\prime} d v_{x}^{\prime}, \beta=i, n, \\
\frac{\partial f_{n}\left(x, v_{x}\right)}{\partial t}+v_{x} \frac{\partial f_{n}\left(x, v_{x}\right)}{\partial x}=n f_{i}\left(x, v_{x}\right) \sigma_{c e}\left(v_{x}\right) v_{x}, \\
v_{x} \frac{\partial f_{r}(x, \vec{v})}{\partial x}=0, \\
j_{d}(x)=j_{i}(x)+j_{e}(x), I_{d}=I_{i}+I_{e}, \\
j_{e}(x)=\left|e \int f_{e}\left(x, \vec{v}^{\prime}\right) v_{x}^{\prime} d v_{x}^{\prime}\right|, j_{i}(x)=\left|e \int f_{i}\left(x, v_{x}^{\prime}\right) v_{x}^{\prime} d v_{x}^{\prime}\right|,
\end{gathered}
$$




$$
\begin{gathered}
I_{e}=\frac{S}{d} \int_{0}^{d} j_{e}(x) d x, \quad I_{i}=\frac{S}{d} \int_{0}^{d} j_{i}(x) d x, \\
E(x)=-\frac{d \varphi(x)}{d x}, \frac{d^{2} \varphi(x)}{d x^{2}}=-\frac{\rho_{e}(x)+\rho_{i}(x)}{\varepsilon_{0}}, \\
\rho_{e}(x)=-e \int f_{e}\left(x, \vec{v}^{\prime}\right) d \vec{v}^{\prime}, \quad \rho_{i}(x)=e \int f_{i}\left(x, v_{x}^{\prime}\right) d v_{x}^{\prime},
\end{gathered}
$$

where $f_{e}, f_{i}, f_{n}, f_{r}$ are the distribution functions of electrons, ions, neutrals after charge exchange and atomic neutrals reflected from the cathode; $x$ is the coordinate axis directed from the cathode to the anode; $v_{x}$ is the projection of the velocity $v$ onto the $x$-axis; $e$ and $m$ are the electron charge and mass, accodingly; $M$ is the mass of the molecular ion; $n$ is the concentration of gas particles (assumed constant); $\delta$ - Dirac delta function; $\sigma_{e}, \sigma_{i}$, $\sigma_{n}$, and $\sigma_{r}$ are the cross sections for gas ionization by an electron, ion, charge exchange neutral, and atomic reflected neutral, besides $\sigma_{n}$ and $\sigma_{r}$ are the sum of the cross sections for gas ionization by neutrals and their stripping; $\sigma_{c e}$ is the ion charge exchange cross section, which takes into account in the case of molecular gases the molecular $A A_{f}^{+}+A A^{0} \rightarrow \mathrm{AA}_{f}^{0}+A A^{+}$and dissociative $A A_{f}^{+}+A A^{0} \rightarrow 2 A_{f}^{0}+A A^{+}$types of the ion charge exchanges by adding the cross sections of both types of charge exchanges, while two fast atomic neutrals were considered equivalent to one non-charged two-atom molecule with the same velosity; $j_{d}$ is the discharge current density; $j_{e(i)}$ is the current density of electrons (ions); $I_{d}$ is the discharge current in the system; $I_{e(i)}$ is the current of electrons (ions); $S$ is the cathode (anode) area; $E$ and $\varphi$ are electric field strength and potential; $\rho e_{(i)}$ is the density of the space charge of electrons (ions); $\varepsilon_{0}$ is the electrical constant. The functional dependences $\sigma_{e}(v), \sigma_{i}(v), \sigma_{n}(v), \sigma_{r}(v)$, and $\sigma_{c e}(v)$ were used in the form of approximations of the corresponding experimental data. For nitrogen, the approximations are given in [2].

The given system of equations is supplemented by the corresponding boundary conditions, the formulation of which depends on the type of the modeled system, and equations for the electric circuit. In the simplest case, the external circuit is a source of constant voltage $U_{s}$, to which a gas-discharge device is connected through a resistor $R_{s}$, and the voltage at the anode is $U=U_{s}-I_{d} \mathbf{R}_{s}$. At the cathode, the following conditions takes place:

$$
\begin{gathered}
j_{e}(0)=j_{e . \gamma}=e\left|\int\left[\begin{array}{l}
\left.\gamma_{i}\left(v_{x}^{\prime}\right) f_{i}\left(0, v_{x}^{\prime}\right)+\right] \\
\gamma_{n}\left(v_{x}^{\prime}\right) f_{n}\left(0, v_{x}^{\prime}\right)
\end{array}\right] v_{x}^{\prime} d v_{x}^{\prime}\right|, \\
f_{e}(0, \vec{v})=\frac{2 j_{e}(0) \delta\left(v^{2}\right)}{e},\left.f_{i}\left(0, v_{x}\right)\right|_{v_{x}>0}=0, \\
\left.v f_{r}(0, \vec{v})\right|_{v_{x}>0}=\underset{\left.f_{n}\left(0, v_{x}\right)\right|_{v_{x}>0}=0,}{\int v_{x}^{\prime}\left[f_{i}\left(0, v_{x}\right)+f_{n}\left(0, v_{x}\right)\right] \Psi\left(\vec{v}, v_{x}^{\prime}\right) d v_{x}^{\prime},} \\
\varphi(0)=0,
\end{gathered}
$$

where $\gamma_{i}$ and $\gamma_{n}$ are the coefficients of the secondary emission of the cathode under the action of bombardment by ions and charge exchange neutrals (in [2], the approximations of the coefficients $\gamma_{i}(v)$ and $\gamma_{n}(v)$ are given); $\Psi$ is the function of the transformation of the spectrums of ions and charge exchange neutrals, bombarding the cathode, into the spectrum of reflected atomic neutrals; here we assume that the reflection of heavy particles does not depend on their charge state. The determination of the spectrum of reflected atoms is described in the Subsec. 2.2. The boundary conditions at the anode depend on the way of organizing the technological process. If the anode is a fine-structured grid, behind which a plasma is created as an ion emitter with current density $j_{i . a}$, the boundary conditions are as the follows:

$$
\begin{gathered}
\left.v f_{e}(d, \vec{v})\right|_{v_{x}<0}=\underset{v_{x}^{\prime}>0}{\int \vec{v}^{\prime} f_{e}\left(d, \vec{v}^{\prime}\right) \mathrm{K}\left(\vec{v}, \vec{v}^{\prime}\right) d \vec{v}^{\prime},} \\
f_{i}\left(d, v_{x}\right)=0, f_{n}\left(d, v_{x}\right)=0, \\
j_{i}(d)=j_{i . a}=\text { Const, } f_{i}\left(d, v_{x}\right)=\frac{2 j_{i}(d) \delta\left(v^{2}\right)}{e}, \\
\varphi(d)=U,
\end{gathered}
$$

where $\mathrm{K}$ is the function of converting the velocity spectrum of electrons, bombarding the anode grid, into the spectrum of reflected electrons. If the anode is the boundary of an open plasma, the additional conditions are introduced:

$$
\mathrm{K}=0, E(0)=0 .
$$

For a given value of $d$, the ion emission current from the plasma $j_{i . a}$ is a calculated parameter. The system with a plasma anode is a model of a cathode layer of a discharge with an anode plasma of the type of a selfsustained high-voltage glow discharge (it may be the anomalous glow discharge - AGD) with plasma generation due to the energy of cathode electrons $[1,3]$ or a non-self-sustained discharge with plasma generation by an $\mathrm{HF}$ or microwave field.

The system of kinetic equations is solved numerically using elements of the "big particles" method [4]. In this case, the general algorithm for solving the problem is divided into several stages, at which independent problems are solved; the algorithm is represented by several iterative loops nested within each other. When solving the problem, we used the multibeam approximation in the "strong field" regime, i.e. it is assumed that the energy of charged particles in the partial flows (beams) is determined by the potential difference passed by the particles from the place of their birth to the place of collision and, under the influence of the field, the particles acquire a directional velocity that is much higher than the chaotic thermal and initial velocities. The voltage $U$ is much higher than the ionization potential of the gas; the energy losses for gas exitation and ionization are neglected due to the low density of the gas. Also, the elastic collisions of ions and fast neutral species are neglected. Thus, it is accepted that the energy of the field is spent only on the acceleration of par- 
ticles. Accordingly, $\lambda_{e, n} r>\mathrm{d}, \lambda_{i} \sim \mathrm{d}$, where $\lambda_{e, i, n, r}$ are the average mean free paths of electrons, ions and neutrals. For the charge exchanges, a "relay race" model of charge transfer from the former ion (becomes as a fast neutral now) to the future ion (but slow yet) is adopted. Thus, this modeling method is a variant of the PiC ("Particles in Cell" $[4,5])$ method, in which the motion of particles with collisions is calculated by the Monte Carlo method in the "strictly forward scattering" approximation under "strong field" conditions.

The use of the developed model for calculating lowpressure ion processing systems made it possible to obtain good agreement with experiment, provided that carefully selected approximations were used for the dependences of the cross sections and coefficients of elementary processes on the particle velocity. In particular, to check the adequacy of the model, the Paschen curve (characteristics of the occurrence of a selfsustained discharge in nitrogen between the metal electrodes) was calculated with the condition $j_{i . a}=0$. Comparison with experiment is shown in Fig. 1. The discrepancy between calculation and experiment in the value of $p d$, at which a self-sustained discharge occurs, does not exceed $10 \%$, which corresponds to the scatter of experimental data [3]. The discharge at $p d$ to the left of the Paschen curve can be maintained in a non-selfsustaining form by injecting an ion flux from the behind anode space into the interelectrode gap by an independent source.

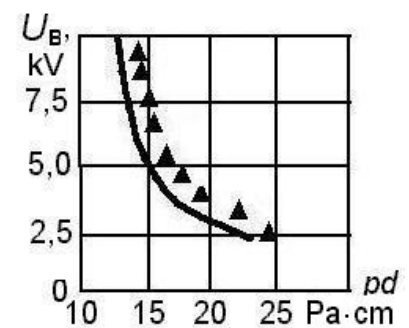

Fig. 1. The Paschen curve (solid line) and experiment (triangles [3])

Fig. 2 depicts typical distribution functions of ion fluxes $v f_{i}$ and charge exchange neutrals $v f_{n}$ towards the cathode. Here, the parameter $d$ is the width of the nearcathode layer of positive space charge (or the dark nearcathode space [1]). The $v f_{i}$ functions contain two parts: the peak for non-recharged ions with energy $e U$ and the dome-like part for ions after one or more charge exchanges. The smaller $p d$, the smaller the 2 nd part of the ion flux, and, accordingly, the smaller the flux of neutral species after ion charge exchanges.

\subsection{SIMULATION OF PROCESSES}

\section{IN THE CATHODE SUBSURFACE LAYER}

To determine the characteristics of the flux of neutral nitrogen atoms reflected from the cathode during the bombardment of the cathode by ions and charge exchange neutrals, we used the physical-kinetic simulation of the motion of bombarding ions and recoil atoms in the subsurface layer of a metal cathode. The simulation is based on the Monte Carlo method in the approximation of linear cascades of pair collisions of atomic particles and the amorphous structure of the cathode body. The calculations were performed using the TRIM pro- gram code [6]. Examples of calculations performed for objects similar to ours are presented in [7 - 10]. Verification of the results of these calculations by comparison with the data known from the literature showed that they are quite adequate, therefore, a conclusion was made about the applicability of TRIM in the given work.

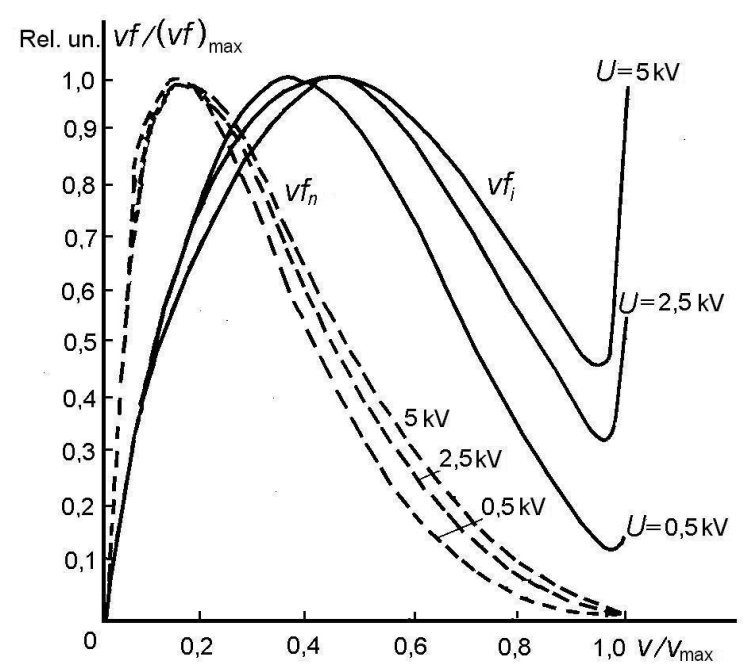

Fig. 2. The distribution functions of ion and neutrals flows after ion charge exchanges at the cathode at $\mathrm{pd}=9 \mathrm{~Pa} \cdot \mathrm{cm}$

The integral reflection coefficients $R$ of fast nitrogen atoms were calculated:

$$
R=\frac{N_{r}}{N_{0}}=\frac{1}{N_{0}} \int_{2 \pi}^{E_{0}} \int_{0}^{E_{0}} F_{r} d \varepsilon d \Omega,
$$

where $N_{0}$ is the number of nitrogen particles bombarding the cathode in terms of atomic particles $\left(\mathrm{N}^{+}\right.$or $\left.\mathrm{N}^{0}\right)$; $N_{r}$ is the number of reflected atoms; $E_{0}$ is the energy of each atomic particle bombarding the cathode; $F_{r}$ is the distribution function of reflected nitrogen atoms in terms of energy and solid angles of ejecting from the cathode body. Table shows the values of the coefficients $R$ at various values of $E_{0}$ for the case of normal incidence of particles accelerated in the interelectrode gap onto a flat tantalum cathode. and, as can be seen, its value is tens percents of units in the entire possible range of energies of the bombarding particles.

It is interesting to note that the value of $R$ for nitrogen particles with an energy of $70 \mathrm{keV}$ is only 2 times less than the value of $R$ for particles with an energy of $0.5 \mathrm{keV}$, i.e. tantalum is an efficient reflector and generator of neutral nitrogen atoms.

Integral reflection coefficient of nitrogen atoms from tantalum

\begin{tabular}{|c|c|c|c|c|}
\hline$E_{0}, \mathrm{keV}$ & 0.5 & 1.0 & 2.0 & 5.0 \\
\hline$R$ & 0.37 & 0.36 & 0.33 & 0.30 \\
\hline$E_{0}, \mathrm{keV}$ & 10.0 & 20.0 & 40.0 & 70.0 \\
\hline$R$ & 0.29 & 0.24 & 0.21 & 0.17 \\
\hline
\end{tabular}

It is known that the discharge plasma in nitrogen emits both atomic $\mathrm{N}^{+}$and molecular $\mathrm{N}_{2}^{+}$ions towards the cathode, but upon impact on the cathode, the molecules decay into atoms, which then independently move 
in the cathode body. Hence, in the case of molecular nitrogen ions $\mathrm{N}_{2}^{+}$, to determine the reflection coefficient, one should use the data for $\mathrm{N}^{+}$ions, but for half the energy $\left(0.5 E_{0}\right)$ and multiply the obtained value $R$ by 2. Similarly, the number of reflected nitrogen atoms should be determined when the cathode is bombarded by charge exchange neutrals, since the initial charge of the bombarding particle is not important for the process of backscattering (reflection) from the cathode.

Fig. 3 shows the energy distributions of reflected nitrogen atoms for a wide range of energies of particles bombarding the cathode. The distributions are presented in the form of histograms, which show the number of $\Delta N$ atoms with energy accordingly to each subrange. The width of subranges are 1/20 of the maximum possible energy $\varepsilon_{\text {r.max }}=E_{0}$ (as the total number of subranges is 20). These histograms, in fact, represent the entire flux of reflected $N_{r}$ atoms to the anode in the form of 20 partial flows of monoenergetic atoms. The calculations were performed for $N_{0}=10^{4}$ atomic particles bombarding the cathode. As can be seen, the nature of the distributions as a whole weakly depends on the value of $E_{0}$; but there is the trend the relative fraction of high-energy reflected atoms from the bombarding particles flow decreases with increasing energy $E_{0}$. This is a consequence of the fact that high-energy particles are implanted deeper into the cathode body, from where the return exit of particles to the surface is associated with large energy losses. Most of the nitrogen atoms reflected from tantalum have energies in the approximate range from $0.1 E_{0}$ to $0.75 E_{0}$.

\section{DISCUSSION OF RESULTS}

Completing the solution to the general problem posed requires stitching the solutions to the problems of modeling processes in the gaseous interelectrode gap and modeling processes in a solid body that is the subsurface layer of the cathode. As a result, one obtains a complete material and energy characteristics of the flux of reflected atoms from the cathode. For this, the spectrum of bombarding particles is to be recalculated (see Fig. 2), namely: the reflected fluxes from each fraction of the entire flux of particles bombarding the cathode are to be calculated and summed up. Since a part of the bombarding flux consists of low-energy species, the total reflected flux is enriched with low-energy nitrogen atoms. This situation is typical for a self-sustained AGD at $p d$ to the right of the left branch of the Paschen curve (see Fig. 1). However, in AGD, with an increase in the discharge current density and $j_{i . a}$, as well, the value of $d$ decreases significantly, as does the number of ion charge exchanges. Therefore, the dense AGD can be used to generate a higher-energy flux of reflected atoms.

The use of a high-voltage glow discharge under conditions, characteristic of the upper part of the left branch of the Paschen curve, promotes the formation of a high-energy flux of reflected atoms both due to the high discharge voltage and due to a decrease in the contribution of ion charge exchanges and of the role of the low-energy part of the flux of ions bombarding the cathode with energies $E_{0}<e U$. In this case, the total energy spectrum of reflected atoms will be almost com- pletely determined only by the histograms shown in Fig. 3 with $E_{0}=e U$.
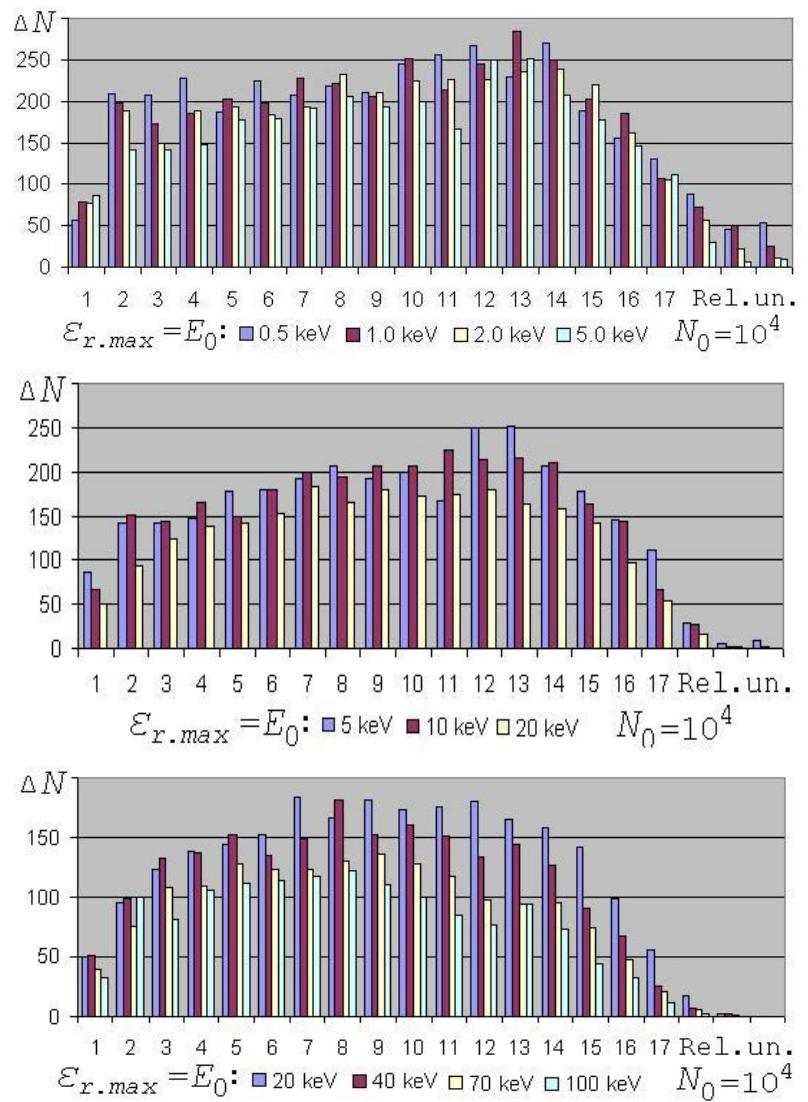

Fig. 3. Histograms of the energy distribution of nitrogen atoms reflected (backscattered) from the tantalum surface

The last equality will be even more strictly fulfilled in the case of using an independent plasma generator behind the anode. In this case, the gas pressure in the interelectrode gap can be greatly reduced and the voltage $U$ may be greatly increased (up to $100 \mathrm{kV}$ ), i.e. to obtain an almost monoenergetic flux of particles bombarding the cathode and a powerful flux of nitrogen atoms, which is suitable for deep implantation into an object opposite the cathode. A high operating voltage naturally leads to an increase in the thermal load on the system and provokes arcing, therefore it is advisable to use a pulsed electrical power supply to the system.

\section{CONCLUSIONS}

A physical-kinetic model of a low-pressure highvoltage beam-like discharge in a nitrogen atmosphere with a tantalum cathode has been formed. Model calculations made it possible to obtain information on the characteristics of the flow of particles bombarding the cathode. A physical-kinetic model of the interaction of bombarding nitrogen particles with the cathode material atoms (of tantalum in our case) in the subsurface layer is applied with use of the TRIM program. This made it possible to obtain information on the characteristics of the flow of neutral nitrogen atoms reflected from the cathode. Both models are based on the application of the statistical Monte Carlo method using approximations for the characteristics of elementary processes of interaction of particles in gas and solid body. 
Calculations have shown that tantalum is an effective reflector and generator of high-energy nitrogen atoms. The reflection coefficient is tens of percents in the range of discharge voltages from hundreds of volts to $100 \mathrm{kV}$.

The data obtained indicate that the use of a highvoltage form of discharge with a tantalum cathode is promising for technological processes of nitriding materials with implantation effects. The absence of charge in the reflected nitrogen atoms makes it possible to recommend processing dielectric materials by the reflected atoms.

\section{REFERENCES}

1. Raizer, P. Yuri. Gas Discharge Physics. BerlinHeidelberg: "Springer-Verlag", 1991, 463 p.

2. V.S. Boldasov, A.I. Kuzmichev, D.S. Fillipychev, A.Yu. Shabarov. Nitrogen gas-discharge electron source with secondary-emission cathode // Radiophys. Quant. Electronics. 1994, v. 37, № 4, p. 19-325.

3. B.N. Klyarfeld, L.G. Guseva, F.S. PokrovskayaSoboleva. Glow discharge at low pressures and current density up to $0.1 \mathrm{~A} / \mathrm{cm}^{2}$ [Tleyushchiy razryad pri nizkih davleniyah i plotnostyah toka do 0.1 A $/ \mathrm{cm}^{2}$ ] // Zhurnal Tehn. Fiziki. 1966, v. 36, № 4, p. 704-713 (in Russian).
4. Yu.N. Grigoriev, V.A. Vshivkov, M.P. Fedoruk. Numerical ssimulation by particles-in-cell methods. Novosibirsk: "Izdatelstvo SO RAN", 2004, 360 p. (in Russian).

5. A. Bogaerts, R. Gijbels. Numerical modeling of gas discharge plasmas for various applications // $\mathrm{Vac}$ uum. 2003, v. 69, p. 37-52.

6. W. Eckstein. Computer Simulation of Ion-Solid Interactions. Berlin: "Springer", 1991, 296 p.

7. E.S. Mashkova, V.A. Molchanov. Scattering of medium energy ions by solid state surface. M.: "Atomizdat", 1980, 256 p. (in Russian).

8. N.V. Pleshivtsev, A.I. Bazhin. The physics of ion beam effect upon materials. M.: "Vuzovskaya Kniga", 1998, 392 p. (in Russian).

9. A. Kuzmichev, V. Perevertaylo, L. Tsybulsky, O. Volpian // J. Phys.: Conf. Ser. 2016, v. 729, p. 012005 .

10. R. Lorenz, M. O'Sullivan, D. Sprenger, et al. Chemical composition and properties of MoAl thin films deposited by sputtering from MoAl compound targets // J. Vac. Sci. Technol. A. 2017, v. 35, p. 041504 .

Article received 08.06.2021

\section{ВЫСОКОВОЛЬТНЫЙ ЛУЧЕВОЙ РАЗРЯД В АЗОТЕ С ОТРАЖЕНИЕМ БЫСТРЫХ НЕЙТРАЛЬНЫХ АТОМОВ ОТ ТАНТАЛОВОГО КАТОДА}

\section{В.С. Болдасов, А.И. Кузьмичев, М.С. Мельниченко, В.М. Шулаев}

Выполнено кинетическое моделирование высоковольтного лучевого разряда при низком давлении азота. Рассчитаны характеристики потоков частиц к танталовому катоду и обратного отражения быстрых атомов азота. Коэффициент отражения составляет десятки процентов при напряжении до 100 кВ. Генерация быстрых атомов азота может быть использована для азотирования металлов и диэлектриков с имплантационным эффектом.

\section{ВИСОКОВОЛЬТНИЙ ПРОМЕНЕВИЙ РОЗРЯД У АЗОТІ 3 ВІДБИТТЯМ ШВИДКИХ НЕЙТРАЛЬНИХ АТОМІВ ВІД ТАНТАЛОВОГО КАТОДА}

\section{В.С. Болдасов, А.І. Кузьмичєв, М.С. Мельниченко, В.М. Шулаєв}

Виконано кінетичне моделювання високовольтного променевого розряду при низькому тиску азоту. Розраховані характеристики потоків частинок до танталового катода і зворотне відбиття швидких атомів азоту. Коефіцієнт відбиття дорівнює десяткам відсотків при напрузі до 100 кВ. Генерація швидких атомів азоту може бути використана для азотування металів і діелектриків з імплантаційним ефектом. 